\title{
Application Research on PVA-ECC in Repairing Airport Pavement
}

\author{
Jianjun Wang ${ }^{1, a}$, Changying Guo ${ }^{2, b}$, Yajun Wang ${ }^{2, c}$
}

${ }^{1}$ The Seventh-Engineering Corps of China Airport Construction, Baoji, 721006, China

${ }^{2}$ Department of Airport, Air Force Service College, Xuzhou, 221006, China

aemail: wangjianjun-hm@163.com, bemail:gcy733 @163.com, ' wyj-1972@163.com

\begin{abstract}
Keywords: Airport Pavement; PVA-ECC; Bond strength;
\end{abstract}
\begin{abstract}
Repair effect by traditional concrete was unsatisfactory on airport pavement due to the weak bonding of old and new concrete pavement and poor crack defects. In this study, which fiber PVA were used as a reinforcing material, it analyzed the repair effect of PVA-ECC with different fiber content in concrete pavement comparatively, established the relationship between the bond strength and fiber content by the linear regression method. It showed that PVA - ECC could meet the requirements of airport pavement repair, bond strength of fiber PVA and cement is the major factor in determining the bond strength of new and old concrete, the established formula could be used as reference for the future construction and test for its higher correlation.
\end{abstract}

\section{Introduction}

Traditionally, ordinary Portland cement concrete was used one grade higher than that of the original in airport pavement repairing; this material has a wide range of sources and easily be constructed, but because its early strength grew slowly, needed long time curing, weak bonding of old and new concrete [1], pavement need to be repaired again soon after the latest repair. Fiber PVA has great ductility and good resistance to temperature and humidity alternation [2,3]. This paper attempts to replace the original repair material by PVA-ECC, in order to compensate for the lack of ordinary Portland cement to enhance the effect of the patch when it is used to repair damaged airport pavement.

\section{Test Design}

There're not any requirements for fiber materials in relevant specification about pavement repair.In this study, repaired specimens were produced by bonding old concrete with PVA - ECC with different fiber content together. At first, it measured the bonding strength at room temperature, analyzed the repair effect of different fiber content and established the relationship between the fiber content and bonding strength. Secondly, it studied repair effect with two indicators as flexural strength and bond strength comparatively.

Test raw materials: P.O 42.5 cement, fly ash level 1 produced in Xuzhou power plant, local river sand, Polycarboxylate super plasticizer, fiber PVA(shown in Fig.1,Table 1), running water, graded crushed stone with diameter $5 \mathrm{~mm}$ to $20 \mathrm{~mm}$ were used as coarse aggregate for underlying concrete, and its apparent density was $2715 \mathrm{~kg} / \mathrm{m}^{3}$, porosity was $35 \mathrm{~kg} / \mathrm{m}^{3}$ (shown in Table 2). M was $4 \mathrm{~mm}$ 、 $5 \mathrm{~mm} 、 4 \sim 6 \mathrm{~mm} 、 6 \mathrm{~mm} 、 8 \mathrm{~mm}$ respectively, in the table.

Table1 Performance of Fiber PVA

$\begin{array}{ccccc}\text { Dry breaking } & \text { Stem } & & \text { Water } & \\ \text { strength } & \text { elongation } & \text { Young's } & \text { Dispersibility } & \text { Length[mm] } \\ {[\mathrm{N} / \text { dtex } \geq]} & \text { at break[\%] } & \text { modulus[cN/dtex } \geq] & \begin{array}{c}\text { reduction } \\ {[\%] \leq}\end{array} & \begin{array}{c}\text { [grade] } \\ \end{array}\end{array}$
10.8 4.0-9.0 290 2.5 1-3 $\mathrm{M} \pm 0.5$

Specimen of underlie concrete. Strength of concrete underlying used to simulate the damaged pavement was C30, according to the requirements of the mix proportion design of cement concrete 
pavement [4], the mixture ratio of concrete in this test were shown in Table 3. The diameter of cylinder specimen was $73.5 \mathrm{~mm}$, and the height was $36.5 \mathrm{~mm}$, there were eight groups of specimen which each group of three (shown in Fig.2). Curing under standard conditions for 28 days, then surface of specimens were roughed to bond with repair material easily. In order to prevent the influence of the test results, specimens were soaked in water so that moisture in repair material PVA-ECC could not be absorbed.

Table2 Gradation of Coarse Aggregate

\begin{tabular}{cccccc}
\hline Mesh[mm] & 2.36 & 4.75 & 9.5 & 16.0 & 19.0 \\
\hline Cumulative Margin [\%] & 99.12 & 98.75 & 81.52 & 15.41 & 0 \\
\hline
\end{tabular}

Table3 Concrete Mix Ratio

\begin{tabular}{ccccccc}
\hline Material & Cement & Sand & Stone & Water & Water-Cement Ratio & Sand Ratio \\
\hline Dosage[kg/m $\left.{ }^{3}\right]$ & 489 & 594 & 1102 & 215 & \multirow{2}{*}{0.44} & \multirow{2}{*}{$35 \%$} \\
Mix Ratio & 1 & 1.21 & 2.25 & 0.44 & & \\
\hline
\end{tabular}

PVA-ECC on the surface. Super plasticizer dosage is $1.75 \%$ of the total gelled material, volume rate of PVA fiber was taken $0,1.37 \%, 1.5 \%$ and $1.37 \%$ respectively. Mixture ratio of PVA-ECC was shown in Table 4. Join fiber soaked fully in water with cement mortar, and stirred evenly, poured them into the mold and vibrated on vibration bench, then the underlying concrete specimen was placed on slurry to be cured under standard condition for 28 days (shown in Fig.3) . Each fiber content of each Specimens do three sets.

Table4 Mixture Ratio of PVA- ECC with Different Fiber Content[g]

\begin{tabular}{cccccccc}
\hline NO. & Cement & $\begin{array}{c}\text { Fly } \\
\text { Ash }\end{array}$ & Sand & Water & $\begin{array}{c}\text { Reducing } \\
\text { Agent }\end{array}$ & $\begin{array}{c}\text { Volume Rate of } \\
\text { PVA [\%] }\end{array}$ & $\begin{array}{c}\text { Weight Ratio of } \\
\text { PVA [\%] }\end{array}$ \\
\hline 0 & 206 & 77.5 & 164 & 119 & 5.7 & 0 & 0 \\
1 & 206 & 77.5 & 164 & 119 & 5.7 & $1.37 \%$ & 4.7 \\
2 & 206 & 77.5 & 164 & 119 & 5.7 & $1.5 \%$ & 5.1 \\
3 & 206 & 77.5 & 164 & 119 & 5.7 & $2.0 \%$ & 6.8 \\
\hline
\end{tabular}

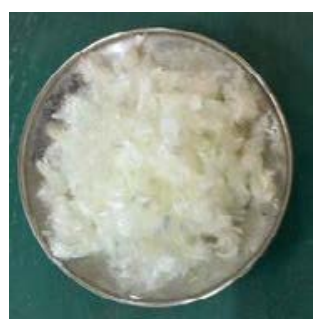

Fig. 1. Fiber PVA

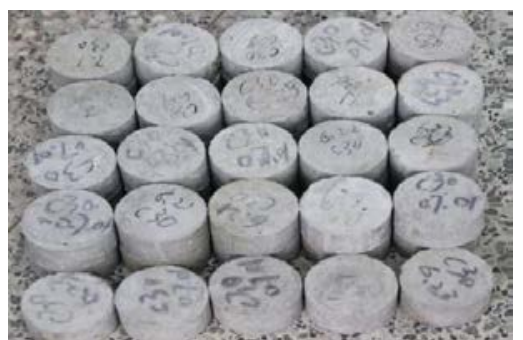

Fig. 2. Specimen of Underlie Concrete



Fig. 3. Specimen of PVA- ECC

\section{The test device and the loading process}

Bond strength was determined by interface performance testerJMS-1and the data collector CJY-F1 (shown in Fig. 4, Fig.5).

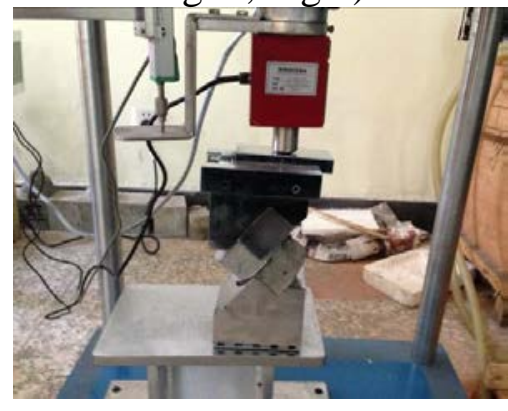

Fig. 4. Interface Performance TesterJMS-1

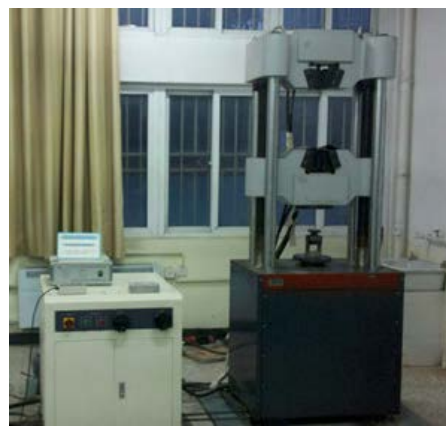

Fig. 5. Universal Testing Machine WAW30600 
The load acquisition range was $0-50 \mathrm{KN}$, loading speed sustained $10-50 \mathrm{~mm} / \mathrm{min}$, the deformation acquisition range was $0-30 \mathrm{~mm}$, resolution was $0.01 \mathrm{~mm}$. Put the new and old concrete cylindrical specimen cut separately on the electro-hydraulic servo universal testing machine to measure their compressive strength, the maximum load was $600 \mathrm{KN}$, the loading rate was $0.1 \mathrm{~mm} / \mathrm{s}$.

\section{Test results and analysis}

Shear failure modes. In bond strength test, specimens without fiber PVA damaged faster and very suddenly, the old and new concrete separated completely accompanying by concrete pieces scattered, destroy interface was clear. PVA-ECC specimens damaged with a longer time, there were not any concrete blocks broken down; bonding surface was stacked with many fibers. Most of the fibers were not pulled off, but was completely pulled out from the concrete. It showed that integrity of PVA -ECC was better than that of normal concrete, bond strength of new and old concrete mainly depended on that of fiber and cement gelled materials instead of fibers PVA [5]. So, the safety of aircraft taking off and landing won't be affected by repair materials damage for this feature.

Shear Stress-Strain Curve: Bonding shear strength of new and old concrete was calculated by formula 1:

$$
\tau=P / S
$$

Where: $\tau$ was bond strength [MPa]; $P$ was the failure load [N]; $S$ was bonded area $\left[\mathrm{mm}^{2}\right]$.

Bond strength-displacement curve measured in experiment for old and new concrete was shown in Fig. 7.It showed that shear stress of the specimens increased with the increase of strain, and the linear increased straightly. Once the adhesion surface was damaged, specimens separated immediately. Maximum failure stress of PVA-ECC specimen was about twice as that of specimen without any fiber. It descripts that fibers improved bond strength significantly. In addition, the shear stress - strain curve of PVA - ECC specimen flattened out, it indicated that shear deformation and toughness were enhanced.

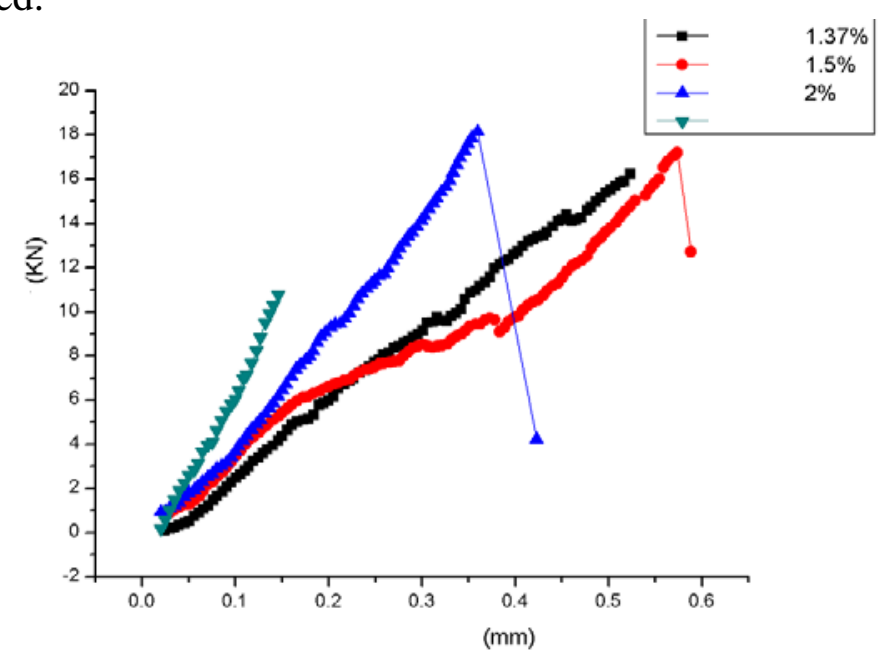

Fig. 7 Shear Stress-Strain Curve of Bonding Specimens

The relationship between fiber content and shear strength of new and old concrete: this experiment adopts the ratio of shear strength of new and old concrete and the corresponding average compressive strength as a measure (Equ.2). Strength test results were shown in Table 5.

$$
\alpha_{2}=\frac{2 \tau_{f}}{f_{c u, o}+f_{c u, n}} \times 100 \%
$$

Where: $\tau_{f}$ was shear strength of old and new concrete; $f_{c u, o}$ and $f_{c u, n}$ was compressive strength of old and new concrete respectively.

Linear regression analysis was carried out on the test data to gain the relationship between fiber volume rate $\beta$ and $\alpha_{2}$ (Equ.3),its correlation coefficient $\mathrm{r}$ was 0.92 , degrees of freedom $\mathrm{f}$ was 2.By Equation 2 and Equation 3, it was concluded that the relationship between shear strength and fiber volume rate(Equ.4). 


$$
\tau_{f}=\frac{f_{c u, o}+f_{c u, n}}{2}(0.86 \beta+2.88)
$$

Table5 Test Results of Strength for New and Old Concrete

\begin{tabular}{cccccc}
\hline NO. & $\begin{array}{c}\text { Volume Rate } \\
\text { of PVA [\%] }\end{array}$ & $\begin{array}{c}\text { Bonding } \\
\text { Strength } \\
\text { [MPa] }\end{array}$ & $\begin{array}{c}\text { Compressive Strength of } \\
\text { New Concrete [MPa] }\end{array}$ & $\begin{array}{c}\text { Compressive Strength } \\
\text { of Old Concrete [MPa] }\end{array}$ & $\alpha_{2}$ \\
\hline J0 & 0 & 2.56 & 50.36 & 39.65 & $2.84 \%$ \\
J1 & 1.37 & 3.82 & 56.31 & 38.75 & $3.97 \%$ \\
J2 & 1.5 & 4.25 & 56.45 & 39.46 & $4.42 \%$ \\
J3 & 2.0 & 4.27 & 55.98 & 41.34 & $4.46 \%$ \\
\hline
\end{tabular}

Comparison of flexural strength and shear strength was shown in Table6.According to the requirements of the mix proportion design of cement concrete pavement; the flexural strength of Airport Pavement must be greater than 5.0MPa. In this test, bonding shear strength of the new and old concrete was less than the corresponding flexural strength of PVA-ECC, so while flexural strength of the repaired specimens has met the requirement above, but it still failed by shear failure. This showed that the shear failure was the principal cause of pavement damaged again after the repair and it should be an important consideration.

Table6 Strength of New and Old Concrete and flexural strength of PVA-ECC

\begin{tabular}{cccc}
\hline NO. & Volume Rate of PVA [\%] & Bonding Strength [MPa] & Flexural Strength[MPa] \\
\hline J0 & 0 & 2.56 & 5.96 \\
J1 & 1.37 & 3.82 & 6.45 \\
J2 & 1.5 & 4.25 & 6.81 \\
J3 & 2.0 & 4.27 & 8.06 \\
\hline
\end{tabular}

\section{Conclusions}

Fiber PVA enhanced the bond strength of new and old concrete and ultimate deformation. When the fiber volume was $2.0 \%$, adhesive strength was the largest, but with the growing of fiber rates the ascending velocity of bond strength slowed down.Bond strength increased $0.02 \mathrm{MPa}$ when the volume rate of PVA changed from $2.0 \%$ to $1.5 \%$, and the relative indicators increased also only $0.04 \%$. In terms of cost savings and facilitate the construction, fiber content $1.5 \%$ was suggested to use in practical construction. Formula established by anglicizing the test data statistically could be used as reference for the future construction and test for its higher correlation. Bond strength between new and old concrete was mainly depended on that between fiber and cement gelled materials but the tensile strength of fibers PVA. Relatively to the flexural strength, it should pay more attention to the bond strength between PVA-ECC and old concrete when it was used to repair cement concrete airport pavement.

\section{References}

[1] Song Teng. Application Research on PVA-ECC in Repairing Airport Pavement[D]. Xuzhou,Air Force Service College,2010.3.

[2] Lepech M, Li V C. water permeability of cracked cementitious composites[C]// CD-Rom, Proceedings of ICFll.Torino.2005. 4539.

[3] Sahmaran M, Li V C. De-icing salt sealing resistance of mechanically loaded engineered cementations composites [J].Cement and Concrete Research.2007.37:1035-1046.

[4] Specifications for Airport Cement Concrete Pavement Design (MH/T5004-2010) [M].China Civil Aviation Authority. 2010.31-33.

[5] Chen Ting. Production and Properties of Cementations' Composites with High-Strength and High Modulus PVA Fiber Reinforcement [D]. Hefei, Hefei Industry University, 2004.6-7. 